\title{
EMERGENCE OF FORM AND FUNCTION IN A VISUAL IMAGE COMBINATION
}

\author{
Mihoko KURAMORI'), Tatsuya IWAKI'), \\ ${ }^{1)}$ Suzugamine Women's College, Japan, ${ }^{2)}$ Hiroshima International University, Japan, \\ and \\ Takashi KUSUMI ${ }^{3)}$ \\ ${ }^{3)}$ Kyoto University, Japan
}

\begin{abstract}
Assuming that the framework in linguistic conceptual combination, such as the head and the modifier of a compound guide the creative process in visual image combination, we focused on the relationship between the constraints of the head or modifier and the emergence of forms and functions of the products. In the experiment, examples of artificial objects and living things were selected as the head and modifier categories that reflect differences in functional constraints. It was treated as artificial object having strong constraints and living things having loose constraints. In this experiment 72 university students were instructed to draw a combination from the two materials presented. The complexity of the form, the novelty of the function and the creativity of the product were assessed. As a result, when artificial objects as heads were combined with living things as modifier, the products displayed a complicated form with a novel function; this combination, therefore, facilitates original and innovative inventions. These findings suggest that the modification of an object with loosed constraints, after establishing the functional significance of the head with strong constraints, is effective and produces inventions.
\end{abstract}

Key words: creativity, emergence, constraint, conceptual combination, imagery

Our lives are filled with creations; but how do we create these new ideas? The creative thinking that produces new ideas is understood to be a transformation of knowledge representations arising from concept manipulation (Boden, 1992, 1995). Transforming knowledge representations is a process of making established concepts more pliable or abstract by, for instance, expanding images (Karmiloff-Smith, 1992). This transformation occurs most often through the combination of existing concepts. This process is known as conceptual combination and involves an enlargement of the meanings or expressions inherent to the knowledge representation in order to recombine established concepts or images (Finke, Ward, \& Smith, 1992).

In a series of studies by Finke et al. on creative thinking (Finke, 1990, 1995; Finke et al., 1992; see also Komazaki, Kusumi, \& Shigemasu, 1998), a model for the process of emergence (the geneplore model) was developed from experiments using simple drawn

Correspondence concerning this article should be addrressed to Mihoko Kuramori, Suzugamine Women's College, 4-6-18, Inokuchi, Nishi-ku, Hiroshima 733-8623, Japan. 
figures. The model described two processes involved in object combination: (1) generative processes, during which creations are imagined, and (2) exploratory processes, undertaken to confirm whether the image agrees with the objective of its creation. Constraints such as the number of compositional elements, or the nature of the functional objective of generated items, were found to improve creativity values (originality and utility) of inventions. It was concluded that such constraints play one of the central roles in creative invention, generally in these studies on creative cognition, generally constraints were operated as an independent variable, and evaluation of generated items as a dependent variable.

On the other hand, prosperous research on conceptual combinations are using a paradigm that takes a compound word (e.g., "clock boat"), formed from the head (""boat") and the modifier ("clock"), and then examines the word's interpretation (e.g., "a boat for timekeeping officials in boat races"). Head and modifier have different functions; the former indicates how we view or think about things, while the latter relates to the specific characteristics of the head things. Conceptual combination research has demonstrated that the particular properties of the structural elements in compound words affect their interpretation and novel concept appearance (Costello \& Keane, 2000; Gagné, 2000; Gagné \& Shoben, 1997; Wisniewski, 1998; Wisniewski \& Love, 1998). Recently Conceptual Blending Theory has been proposed as a model for a variety of cognitive activities. In Conceptual Blending (CB), elements from different mental spaces are aligned with one another as well as selectively projected to a blended space, yielding emergent meaning (Fauconnier \& Turner, 1998, 2002).

To create the novel concept in a compound word, incongruity between elements is important. Incongruity indicates dissimilarity or difference in category of the word's concept. Wilkenfeld and Ward (2001), in a study that focused on emergence in the interpretation of $\mathrm{CB}$, examined the effect of categorical similarity between elements ("shovel bird" examples, "a plane that scoops up water from lakes to dump on fires"). They concluded that low similarity of elements led to frequent mapping modifications, and produced more emergent features, due to changes in interpreting the head, which determines the direction of the overall interpretation. Costello and Keane (1997) revealed that artificial categories of the head produced more interpretations of the compound word than that of living category of head. Norman $(1998,1991)$ indicated that when we use or remodel artificial objects, we perceive the various constraints of those objects. For example, when comparing artificial objects and living things, the principal function of an artificial object emerges as the salient feature, while living things possess various functions. Categorical characteristics depend upon the strength or weakness of internal relationships between those functions (Gelman, 1989; Hauser, 1997; McRae, deSa, \& Seidenberg, 1997). Relatively speaking, then, while the category of artificial objects is controlled by constraints that actualize their functions, living things belong to a category with looser constraints. By combining dissimilar categories such as the respective categories (artificial/living) for the head and modifiers, this enhances the creative interpretation in compound words (Costello \& Keane, 1997).

Studies of a concept combination using compound words are actually suited because 


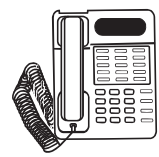

Telephone

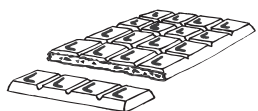

Chocolate bar

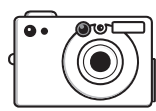

Camera

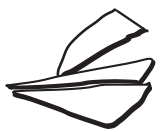

Broken glass
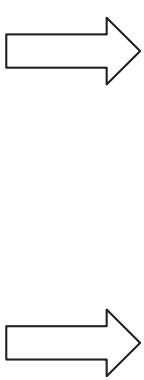

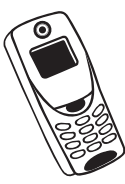

Cellular phone

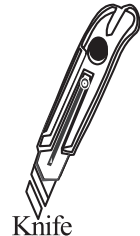

Fig. 1. The example of combination between existing products.

the use of constructed concept to find an existing reference in the preceding discourse context is usual and natural(Costello \& Keane, 2000). Finke et al. (1992) have studied whether practical and/or sensible objects are created from the combination of simple drawn figures. Simple figures do not have a clear concept for its function but they do have a visual form. Results of conceptual combination using compound words seem to be consistent with the combination of simple figures. However, it has not been confirmed that the results of conceptual combination using compound words apply to the combination of visualized concept of a word. In real life, many products exist as a result of combination between existing products like cellular phone with camera, notebook computer, etc. Especially, the knife of the Olfa Co. is famous as the product that synthesizes the feature of "Broken glass" and "Chocolate bar". In such case, not only the function of the metaphor in a compound word but also the physical forms in combining the concept need to be considered. Although this way is very simple, it might be a driving force to invent a more convenient thing.

Therefore, the present study examined whether combination strategy of linguistic conceptual combination could apply to mental synthesis of concrete object in the invention for functional improvement. In this study, as a framework for analyzing the creation of inventions, inventions are defined as consisting of two elements with differing constrained conditions, i.e., a head and a modifier; thus, the conditions for the emergence of inventions are clarified. Specifically, artificial objects and living things are examined as categories with different degrees of function-actualizing constraints. We examined the differences in form, emergent function, and the utility/originality evaluation of the inventions created, by combining the respective categories (artificial/living) of the head and modifiers, and we investigated whether creating inventions derives from the interaction between the constraints of the two types of elements.

We hypothesized that the 1) creativity evaluation would be higher in combinations of different categories (artificial + living) than that of same categories (artificial + artificial and living + living) if function-actualizing constraints would affect emergent activities. 
Moreover, in the case of different categories combinations, 2) creativity evaluation would be higher in artificial heads than that of living head because it was considered that the higher constraint head is more likely to decide the directionality of function of inventions.

In the present study, it was hypothesized that constraints based on knowledge representations of the respective elements closely related to the emergence conditions of the inventions. Then, we attempted to clarify that the emerged conceptual combinations were associated with an interaction between head and modifiers similarly to linguistic conceptual combination even if the head and modifiers were presented as figures.

\section{METHODS}

Participants: 72 Japanese undergraduate and graduate students participated in the experiment.

Materials: Three artificial objects (AO) and three living things (LT), total six object drawings served as head and modifiers (Table 1). Participants took part in two of the four conditions $(\mathrm{AO}+\mathrm{AO}, \mathrm{AO}+\mathrm{LT}$, $\mathrm{LT}+\mathrm{AO}, \mathrm{LT}+\mathrm{LT})$ described below. Each condition contained nine combinations, and each participant conducted a conceptual synthesis on three of those combinations. The allocation of conditions and combinations was randomly determined. As each participant performed a total of six syntheses (2 conditions $\times 3$ combinations), 12 data were collected for each of the nine possible combinations in each of the four conditions.

Procedures: Participants were given six-page booklets. On each page the artificial objects and/or living things, which were to serve as the head and modifiers, were represented in the drawings. Regardless of whether combinations would be possible or impossible in reality, participants were directed to (1) conceptually combine the head and modifiers to create "meaningful (useful)" and "interesting" inventions, and (2) draw a picture of their creation and write a description. Participants were instructed to: "Incorporate (combine) the bird (A) into the bag (B) to produce a useful and interesting invention. Then, draw a picture of the combined product and add a written description. Participants were instructed to incorporate A into B, B was designated as the head, while A constituted the modifier. For example, "create both meaningful (useful) and interesting inventions by incorporating bird into bag. A bag can be thought to have the functions of containing and carrying things. A bird shows two major functions; it can fly by flapping its wings, or grasp things with its beak. Please explain which capabilities (functions) of the bird or the bag you have focused on, and how you combined these functions in order to make an invention with useful and interesting capabilities (functions)." Participants were allowed to work individually and at their own pace. There was no time limit, but participants generally took about 30 min to complete the task.

Evaluations and Analysis: Conceptual combination is conducive to creating new characteristics and forms, but these emergent properties are not always useful (Finke et al., 1992). In other words, new qualities and shapes can be produced, but may lack novelty or practical meaning. Therefore, evaluations of both form/

Table 1. Experimental Materials

\begin{tabular}{cl}
\hline \multicolumn{1}{c}{ Head } & \multicolumn{1}{c}{ Modifier } \\
\hline AO (bag, book, house) & AO (pocket, chimney, wheel) \\
AO (bag, book, house) & LT (bird, elephant, men) \\
LT (fish, alligator, horse) & AO (pocket, chimney, wheel) \\
LT (fish, alligator, horse) & LT (bird, elephant, men) \\
\hline
\end{tabular}

$\mathrm{AO}=$ Artificial Object LT $=$ Living Thing 


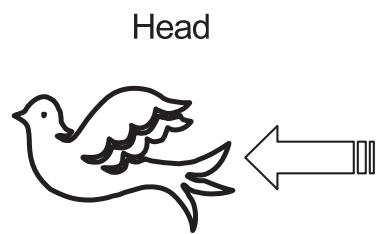

Living thing

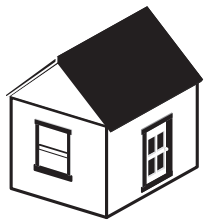

Artificial Object

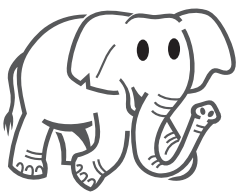

Living thing

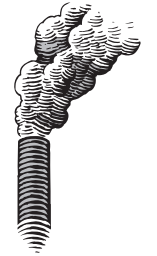

Artificial Object
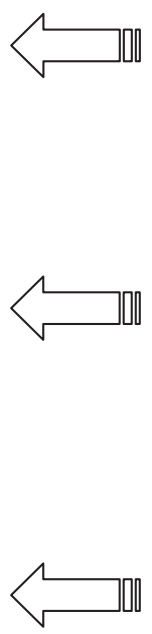

\section{Modifier}

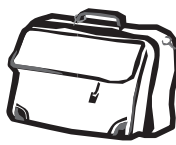

Artificial Object

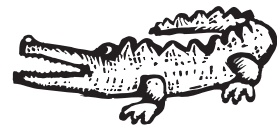

Living thing

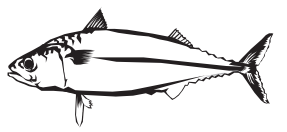

Living thing

Fig. 2. The example of combination the head and modifier

function and creativity were conducted. On the basis of the drawings and written descriptions completed by the participants, three raters were asked to rate: (1) the form and function of the invention, and (2) its creativity ("originality" and "utility")

Form and Function of the Inventions:

a) Form of the Inventions: Raters judged whether a complex or a simple change had been made, as compared with the original elements in their individual states. Changes were considered complex when one element was included in or combined with the other (e.g., bag + bird = a bag with wings). Changes were considered simple when constituent elements were only arranged (vertically or horizontally) adjacent to each other (e.g., fish + chimney $=$ a fish with a chimney attached)

b) Function of the Inventions: Raters judged whether the function of the head had been improved or not (absence/presence of new functions). The bag with bird's wings is an example of a new function. When the bag becomes heavy due to its contents, the wings flap and lighten the load. This is the discovery of a function not previously attributed to a bag. The fish with a chimney attached to it is an example that lacks new functions. While the chimney may augment the fish's gills as a secondary means of breathing, this does not constitute a new function.

The inter-rater reliabilities for form and functions were .92 and .83 , respectively. In cases of disagreement between the raters, the data were based on agreement between two raters.

Creativity of the Inventions: Based on previous study (Finke, 1990), creativity was rated from two factors, "utility" (meaningful, useful) and "originality" (interest, novelty). The three raters judged each aspect of the invention on a five-point scale ranging from 1(Inapplicable) to 5(Applicable). Their mean 
Table 2. The Example of Evaluation the Form, Function and Creativity ("Originality" and "Utility") of the Invention

\begin{tabular}{|c|c|c|c|c|}
\hline Evaluation Items & \multicolumn{4}{|c|}{ Combinations (Head + Modifier) } \\
\hline Constructive elements & $\begin{array}{c}\mathrm{AO}+\mathrm{AO} \\
\text { house, pocket }\end{array}$ & $\begin{array}{l}\mathrm{AO}+\mathrm{LT} \\
\text { bag, bird }\end{array}$ & $\begin{array}{c}\mathrm{LT}+\mathrm{AO} \\
\text { fish, chimney }\end{array}$ & $\begin{array}{c}\mathrm{LT}+\mathrm{LT} \\
\text { elephant, alligator }\end{array}$ \\
\hline Drawing & & & & \\
\hline Special features & $\begin{array}{l}\text { A pocket sticks to } \\
\text { the roof of the } \\
\text { house and can save } \\
\text { water }\end{array}$ & $\begin{array}{l}\text { Wings are } \\
\text { mobilized and the } \\
\text { bag is lifted when } \\
\text { the bag becomes } \\
\text { heavy }\end{array}$ & $\begin{array}{l}\text { A fish breathing } \\
\text { through the } \\
\text { chimney protruding } \\
\text { from the gills }\end{array}$ & $\begin{array}{l}\text { An elephant having } \\
\text { sharp teeth, tough } \\
\text { skin and noxious } \\
\text { tail to attack } \\
\text { opponents }\end{array}$ \\
\hline Form of invention & simple & complex & simple & complex \\
\hline Function of invention & $\begin{array}{l}\text { absence of } \\
\text { novelty }\end{array}$ & $\begin{array}{l}\text { presence of } \\
\text { novelty }\end{array}$ & $\begin{array}{l}\text { absence of } \\
\text { novelty }\end{array}$ & $\begin{array}{l}\text { presence of } \\
\text { novelty }\end{array}$ \\
\hline $\begin{array}{c}\text { Mean utility score } \\
\text { on evaluation }\end{array}$ & 3.5 & 3.9 & 2.9 & 3.4 \\
\hline $\begin{array}{l}\text { Mean originality score } \\
\text { on evaluation }\end{array}$ & 2.4 & 3.0 & 2.2 & 2.7 \\
\hline
\end{tabular}

scores were $2.66(S D=1.01)$ and $2.136(S D=1.02)$, respectively, for utility and originality. The inter-rater reliability used among raters was .73 for originality and .76 for utility.

To simplify and consider the consistency in the method of analysis, scores derived from the five-point scale were converted to a nominal scale. From the frequency distribution of the scores for utility and originality, inventions that surpassed one of the median scores ( 9.00 for utility, 8.00 for originality) were defined respectively as "utility" or "original" inventions, while those surpassing both medians were defined as "creative" inventions.

Constraint evaluation of materials used in the experiment: 14-page booklets were distributed to a new group of 26 undergraduate participants. Participants were instructed to identify and write down as many elements (functions) of the objects depicted in the illustrations as they could. To explain the task, the first two pages contained pictures of a clock (artificial object) and a dog (living thing), with sample answers. The sample answers for the clock were: (1) it tells us the time of day, (2) it measures time, (3) it teaches us about numbers, and (4) it serves as a (paper) weight. Those given for the dog were: (1) it barks, (2) it holds/carries things in its mouth, (3) it bites, (4) it warms one's body when hugged or held. On the remaining 12 pages, in random order, were the previously described 12 illustrations employed in the experiment. Participants were allowed to work individually, at their own pace, without any time limit, taking an average of about 15 minutes to complete the task. When participants had questions during the exercise, they were instructed to refer to the sample problems.

Thagard and Verbeurgt (1988) reported that the degree of constraint is related to the number of elements. This study focused on the constraints that reveal or actualize the functions of things. We believed that we could evaluate the constraints inherent in the materials used by considering the number of elements identified as described. 
Table 3. Mean Numbers of Functions of 12 Materials Used in the Experiments ( $n=26$ for Each Material)

\begin{tabular}{|c|c|c|c|c|c|c|c|c|c|}
\hline \multirow{3}{*}{$\begin{array}{c}\text { Category } \\
\begin{array}{c}\text { Artificial } \\
\text { Object }\end{array}\end{array}$} & \multicolumn{4}{|c|}{ Head } & \multicolumn{4}{|c|}{ Modifier } & \multirow[t]{2}{*}{$\begin{array}{l}\text { Total } \\
\text { Mean }\end{array}$} \\
\hline & bag & book & house & mean & pocket & chimney & wheel & mean & \\
\hline & 4.3 & 5.0 & 4.6 & 4.63 & 3.9 & 4.1 & 4.2 & 4.07 & 4.35 \\
\hline Living & fish & alligator & horse & mean & bird & elephant & men & mean & \\
\hline Thing & 4.9 & 4.9 & 5.2 & 5.00 & 5.2 & 5.0 & 5.6 & 5.26 & 5.13 \\
\hline
\end{tabular}

\section{RESULTS}

We first verified the precondition that degrees of function-actualizing constraints differed between artificial objects and living things. We then noted the effects of the categories (artificial/living), with respect to the head and modifiers, on the form and emergent function of the inventions. Although form and emergent function are important factors, they do not necessarily lead to invention. Finally, the utility and originality of inventions were examined as creativity.

\section{Constraints of experimental materials}

The degree of constraint is related to the number of elements (Thagard \& Verbeurgt, 1998). According to the mean number of functions listed (Table 3), differences between the categories were analyzed using an element (head/modifier) $\times$ category (artificial object/living thing) ANOVA. The main effect of category was significant $(F(1$, $25)=6.73, p<.05)$. This main effect of category reflects the constraints on living things are weaker than those on artificial objects in terms of the number of functions.

\section{Form and function of the inventions}

To survey the relation of the head (artificial object/living thing) and modifier (artificial object/living thing) categories with the form (simple/complex) and function (absence/presence of novel function) of the inventions, a Multiple Correspondence Analysis (MCA), was conducted using Statistica (Model-1999, Statsoft Manufacturing Co. Ltd.). MCA is a graphical technique to show which rows or columns of a frequency table have similar patterns of counts.

A total of 432 cases ( 36 combinations $\times 12$ participants) were derived from the respective forms (simple/complex) and functions (absence/presence of novel function) of the inventions to yield a $0-1$ data matrix. Figure 3 shows the location for each 36 combinations on a two dimensional plane. The first dimension indicated the category of modifiers, since the modifiers as a living thing category were located in the positive direction, while modifiers as an artificial object category were located in the negative direction. The second dimension indicated the category of heads, since the heads as a living thing category were located in the positive direction and that heads as an artificial object category were located in the negative direction. 


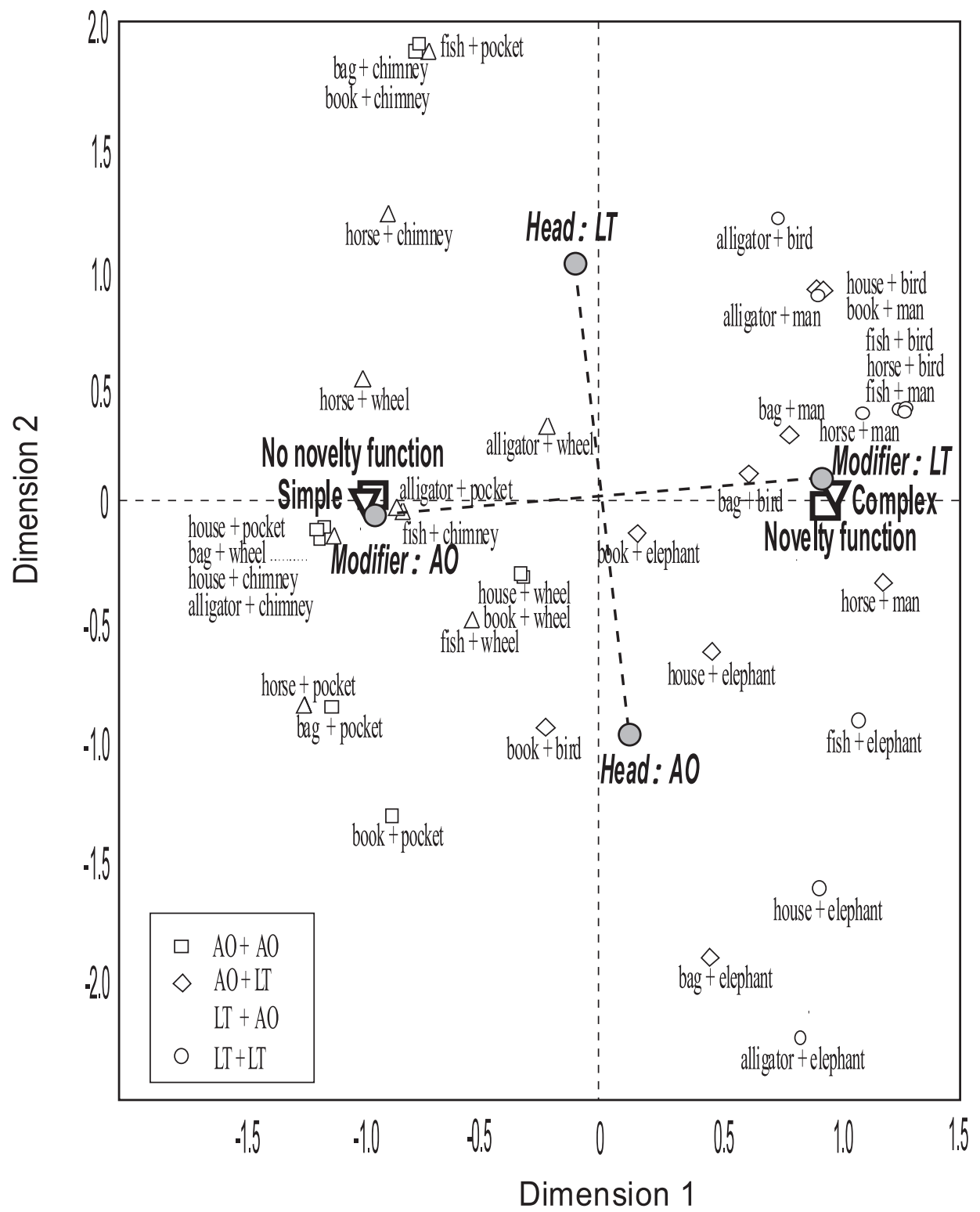

Fig. 3. Correspondence analysis plot for the form and function of the inventions: relationships of head and modifier with form (simple/complex) and function ( presence/absence of novelty) of inventions involving artificial object + artificial object $(\mathrm{AO}+\mathrm{AO})$, artificial object + living thing $(\mathrm{AO}+\mathrm{LT})$, living thing + artificial object $(\mathrm{LT}+\mathrm{AO})$ and living thing + living thing $(\mathrm{L} \mathrm{T}+\mathrm{LT})$.

To enhance understanding, contingency tables of the four sets of head (artificial object/living thing) and modifier (artificial object/living thing) categories were also analyzed with the MCA. Pooled tendencies of the 36 combinations were reconfirmed 
Table 4. The Percentage (\%) of Complexity in Form, Novelty in Function and Complexity Coupled with Novel Functionality of an Invention $(n=108$ for Each Item) Involving Artificial Object (AO) and Living Thing (LT).

\begin{tabular}{lrccc}
\hline \multirow{2}{*}{ Evaluation Items } & \multicolumn{4}{c}{ Combinations (Head + Modifier) } \\
\cline { 2 - 5 } & $\mathrm{AO}+\mathrm{AO}$ & $\mathrm{AO}+\mathrm{LT}$ & $\mathrm{LT}+\mathrm{AO}$ & $\mathrm{LT}+\mathrm{LT}$ \\
\hline Complexity & 10.1 & 74.7 & 9.1 & 94.9 \\
Novelty & 20.2 & 70.7 & 22.2 & 88.0 \\
Complexity \& Novelty & 9.0 & 66.7 & 8.0 & 84.8 \\
\hline
\end{tabular}

when results were overlapped and plotted in Figure 3. The first- and second -dimensions' contributions of the modifier and head categories were $60.0 \%$ and $25.0 \%$, respectively. It appeared that, with the first dimension, $60.0 \%$ of the inertia can be explained, that is, the effect of modifier categories on the form and function of the inventions were greater than that of head categories. Moreover, the distances of the points on the two-dimensional plane which are informative, explain similarities and differences between variables. Based on the findings that a living thing modifier placed near complexity of form and novelty of function, and the reverse, an artificial object modifier placed near simplicity of form and non-novelty of function, the modifier category would affect the complexity in form and the novelty of function with respect to the invention. However, the novelty of the correlation between the head category and the form/function of the invention was weak.

To confirm tendencies noted in the MCA, the rate of an invention judged that its form was complex that its function was novel, and that of complexity with novelty were calculated for each conditions and displayed in Table 4.

By performing this rate arc sine transformation and exploiting $\chi^{2}$ distribution, an ANOVA of the head (artificial object/living thing) and modifier (artificial object/living thing) categories was performed. There were significant interactions between head and modifier categories for the percentages of complexity $\left(\chi^{2}(1)=9.9, p<.01\right)$, novelty $\left(\chi^{2}(1)=4.3, p<.01\right)$ and complexity with the novelty $\left(\chi^{2}(1)=5.4, p<.01\right)$ of the inventions. Simple main effect tests of the head category for the percentages of complexity, novelty and complexity with novelty revealed that the modifier category was not significant in the case of artificial object $(\mathrm{AO}+\mathrm{AO}$ vs $\mathrm{LT}+\mathrm{AO})$. However, it was significant in the case of living things $\left(\mathrm{AO}+\mathrm{LT}\right.$ vs LT + LT: $\chi^{2}(1)=17.8, \rho<.05$, $\left.\chi^{2}(1)=10.1, \rho<.05, \chi^{2}(1)=9.2, \rho<.01\right)$. This means that head categories affected the form and novelty function of invention when modifier was a living thing. Same tests of the modifier category for the percentages of complexity, novelty and complexity with novelty indicated that the head category in the both case of artificial object $(\mathrm{AO}+\mathrm{AO}$ vs $\left.\mathrm{AO}+\mathrm{LT}: \chi^{2}(1)=213.1, \rho<.01, \chi^{2}(1)=108.4, \rho<.01, \chi^{2}(1)=154.2, \rho<.01\right)$ and living thing $\left(\mathrm{LT}+\mathrm{AO}\right.$ vs LT $+\mathrm{LT}: \chi^{2}(1)=102.9, \rho<.01, \chi^{2}(1)=56.2, \rho<.01, \chi^{2}(1)=83.4$, $\rho<.01)$ were significant. Modifier categories affected the form and functional novelty 
regardless of the kind of the head categories. The MCA using Tukey's method indicated that either the rate of the complexity in form, the novelty in function, or the complexity coupled with novelty of an invention, was related to the following in an ascending order of significance $(p<.01): \mathrm{LT}+\mathrm{LT}<\mathrm{AO}+\mathrm{LT}<\mathrm{AO}+\mathrm{AO} / \mathrm{LT}+\mathrm{AO}$. The complexity in form and the novelty in function were urged by the condition that the modifier category was a living thing.

Furthermore, to determine the relationship between the rated percentage of complexity and functional novelty and the degree of constraint, correlation analysis between mean rates of complexity and novelty and the functional number of materials employed for head and modifiers were performed. The functional number of modifiers correlated significantly both with the percentage of complexity $(r(34)=.918, p<.01)$ and functional novelty $(r(34)=.890, p<.01)$, while that of heads were not significant. This indicates that the degree of constraint of a modifier affected the complexity in form and the novelty in function of the invention.

\section{Creativity Evaluation of the Inventions}

The relation of utility, originality and creativity (utility with originality) of inventions with head (artificial object/living thing) and modifier (artificial object/living thing) categories were analyzed in the same way as used in analysis of form and function.

Analysis for 36 possibilities in the lower combinations using MCA provided that the first component indicated the category of modifiers and the second component indicated the category of heads (Figure 4). By overlapping the results of analyses of data pooled from each four-set finding, of the 36 combinations, with the results displayed in Figure 4, first- and second-dimensions' contributions were $53.3 \%$ and $23.3 \%$, respectively. The points of originality and creativity were located near a living thing modifier, and the points of utility were located in the middle between the points of living thing modifiers and artificial object head. When the modifier was a living thing category (Fig. 4), inventions were perceived to be more useful, original and creative. However, when the head was the artificial object category, inventions were perceived to be useful.

To confirm the results of the MCA, the respective percentages for each set of the utility, original and creative inventions were derived (Table 5). After performing this rate arc sine transformation, an ANOVA of head category (artificial object/living thing) $\times$ modifier category (artificial object / living thing) employing the $\chi^{2}$ distribution was performed. The results revealed a significant interaction $\left(\chi^{2}(1)=14.1, p<.05\right)$ between head and modifiers with respect to utility inventions. Significant effects resulted from a simple main effects analysis of head categories, in both cases, where the modifier category was either an artificial object or a living thing ( $\mathrm{AO}+\mathrm{AO}$ vs $\mathrm{LT}+\mathrm{AO}$ : $\chi^{2}(1)=11.7, p<.01 ; \mathrm{AO}+\mathrm{LT}$ vs LT $\left.+\mathrm{LT}: \chi^{2}(1)=76.4, p<.01\right)$. This indicated that artificial object head led the utility of inventions regardless of modifier categories. Moreover, in the simple main effects analysis of the modifier category, a similar tendency was confirmed: effects were significant whether the head category was of artificial objects or living things $\left(\mathrm{AO}+\mathrm{AO}\right.$ vs $\mathrm{AO}+\mathrm{LT}: \chi^{2}(1)=5.06, p<.05$; LT $+\mathrm{AO}$ vs $\mathrm{LT}+\mathrm{LT}$ : $\left.\chi^{2}(1)=57.3, p<.01\right)$. This indicated that living thing modifier also led the utility of 


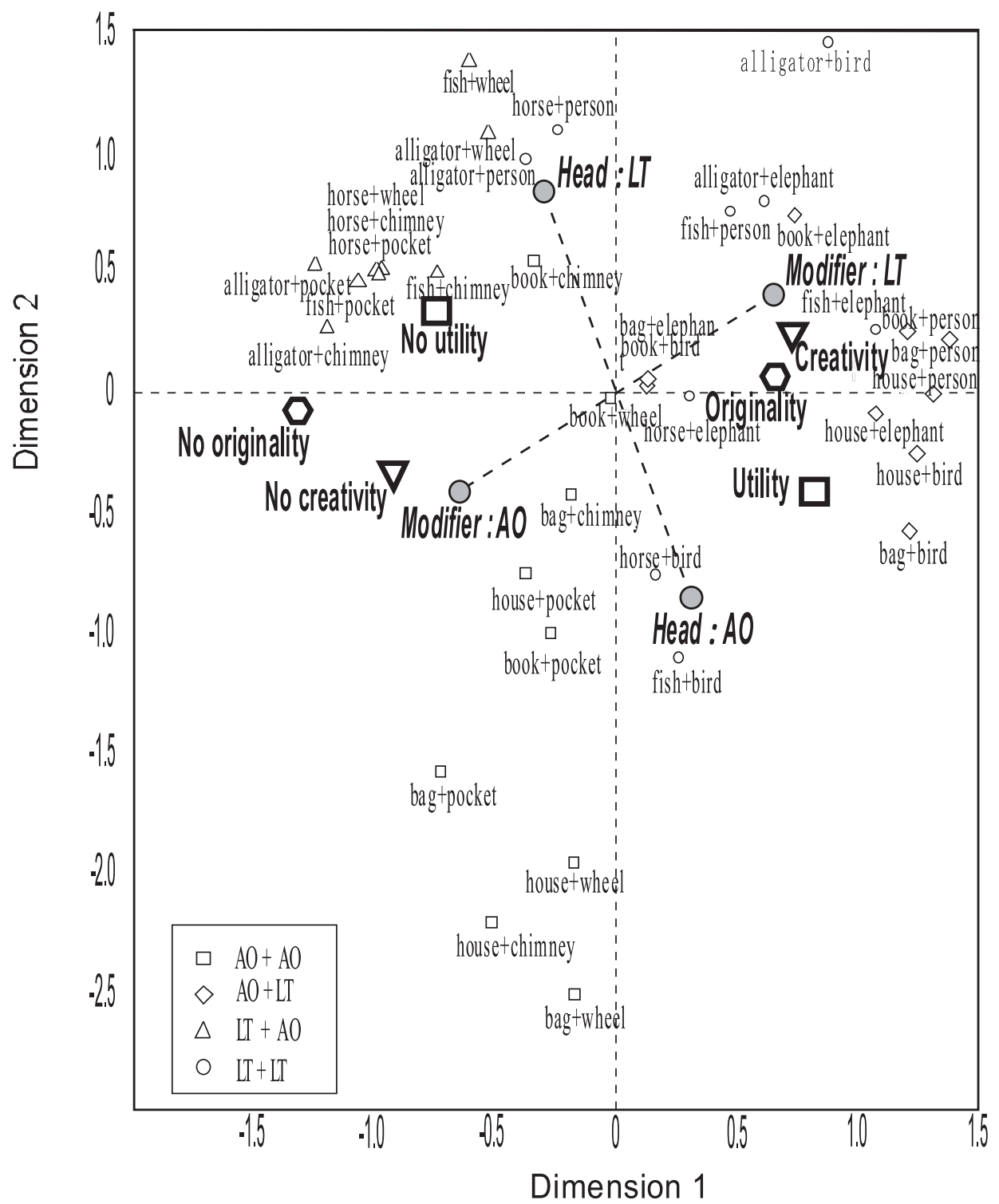

Fig. 4. Correspondence Analysis Plot for the Creativity Evaluation of the Inventions: Relationships of head category and modifier category with utility (presence/absence of utility), creativity (presence/ absence of utility) and originality (presence/absence of originality) of inventions involving artificial object + artificial object $(\mathrm{AO}+\mathrm{AO}), \quad$ artificial object + living thing $(\mathrm{AO}+\mathrm{LT})$, living thing + artificial object $(\mathrm{LT}+\mathrm{AO})$ and living thing + living thing $(\mathrm{L} \mathrm{T}+\mathrm{LT})$.

invention regardless of head categories. The results of the multiple comparisons using Tukey's method revealed significant effects $(p<.05)$ in the rate of utility invention for the following in an ascending order: $\mathrm{AO}+\mathrm{LT}<\mathrm{LT}+\mathrm{LT}<\mathrm{AO}+\mathrm{AO}<\mathrm{LT}+\mathrm{AO}$. The combination of artificial objects head with living things modifier might bring the utility of 
Table 5. The Percentage (\%) of Perceived Utility, Creativity and Originality of Inventions for an Innovated Product (Each Item $N=108$ ) Involving Artificial Object (AO) and Living Thing (LT).

\begin{tabular}{lcccc}
\hline \multirow{2}{*}{ Evaluation Items } & \multicolumn{4}{c}{ Combinations (Head + Modifier) } \\
\cline { 2 - 5 } & $\mathrm{AO}+\mathrm{AO}$ & $\mathrm{AO}+\mathrm{LT}$ & $\mathrm{LT}+\mathrm{AO}$ & $\mathrm{LT}+\mathrm{LT}$ \\
\hline Utility & 65.6 & 79.85 & 10.1 & 57.6 \\
Originality & 19.2 & 71.7 & 16.2 & 62.6 \\
Creativity (Utility \& Originality) & 16.2 & 65.7 & 7.1 & 31.3 \\
\hline
\end{tabular}

Note: The original invention is defined as an invention with creativity and utility.

invention.

In the evaluation of originality, only the main effect of modifier category was significant $\left(\chi^{2}(1)=100.3, p<.01\right)$. Based on multiple comparisons, original inventions were rated significantly higher $(p<.05)$ when the modifier category was a living thing rather than an artificial object.

There were significant interactions between head and modifier $\left(\chi^{2}(1)=8.9, p<.05\right)$ on the perception of creative invention. The pattern of interactions was nearly the same as the result of utility analysis. An analysis of the simple main effect of the head category yielded significance for the modifier category $\left(\mathrm{AO}+\mathrm{AO}\right.$ vs LT $+\mathrm{AO}: \chi^{2}(1)=24.4$, $p<.01 ; \mathrm{AO}+\mathrm{LT}$ vs LT $\left.+\mathrm{LT}: \chi^{2}(1)=4.1, p<.05\right)$ in both living things and artificial object scenarios. Even with the simple main effect of modifier category, significant effects were found for both artificial objects and living things $\left(\mathrm{AO}+\mathrm{AO}\right.$ vs AO + LT: $\chi^{2}(1)=55.8$, $p<.01 ;$ LT + AO vs LT + LT: $\left.\chi^{2}(1)=20.9, p<.01\right)$. The percentages of creative invention were significant in multiple comparisons $(p<.05)$, in the following ascending order: $\mathrm{AO}+\mathrm{LT}<\mathrm{LT}+\mathrm{LT}<\mathrm{AO}+\mathrm{AO}<\mathrm{LT}+\mathrm{AO}$. In other words, creative inventions are most likely to be produced in the artificial object + living thing combination.

Correlation of the ratings of utility and originality with the function number of materials of head and modifier objects, yielded a significant correlation coefficient between the function number of modifier and the rate of utility $(r(34)=.457, p<.01)$ and originality $(r(34)=.841, p<.01)$. On the other hand, correlation coefficient between the function number of head objects and utility was negative while there was no significance $(r(34)=-.172, n . s$.$) . This indicated that the constraint of the modifier affected the utility$ and originality of the invention.

\section{Discussion}

In the present study, it was hypothesized that constraints based on knowledge representations of the respective elements closely related to the emergence conditions of the inventions. Then, we attempted to clarify that the emergence of conceptual 
combinations was associated with an interaction between head and modifiers similar to linguistic conceptual combination even if head and modifiers were presented as figures.

Comparisons between different and same categoric combinations indicated that evaluation of creativity was highest in the combination of artificial object head with living thing modifier, while that in the combination of living thing head with artificial object modifier was lowest. In addition to this, the combination living things + living things had higher evaluation in complicated form and novel function of inventions. Although the differential combination did not necessarily bring emergent creativity, first hypothesis was partially supported in regard to the combination of AO + LT.

As for constraints, regardless of the head or modifier, differences were found to influence the creativity of inventions when comparing combinations of living thing + living thing and living thing + artificial object categories. Because function imposes a strict constraint on artificial objects while exerting a mild influence on living things, artificial object + artificial object presents the most severe constrained combination, while living thing + living thing offers the situation in reverse. The function number of materials employed in the experiment confirmed this tendency. Complexity and novelty in inventions were facilitated by the living thing + living thing combination, suggesting the creations of novel products.( Furthermore, although there was no difference between the two combinations with respect to rated utility of invention, the living thing + living thing combination (31.3\%) manifested a two-fold rate in judged creativity, as compared with the artificial object — artificial object combination (16.7\%), suggesting that a condition with mild constraints is more closely related to creative invention than conditions with strict constraints). Combining potent constraining elements such as the artificial object-artificial object combination results in significant utility, but the combination is creatively deficient. Contrarily, employing mild constraints of the living thing-living thing combination, this facilitates the incorporation of utility into creativity of inventions.

However, our comparison of the combinations of artificial objects with living things and living things with artificial objects in the present study, depending on the distribution of either the head or modifiers, resulted in a substantial discrepancy with respect to complexity of form, novelty of function and creativity, even if the categories were the same for combination. If a similar result would obviously be yielded for two combinations, the concept of head and modifiers prove meaningless. In conceptual combination, the problem of whether it is appropriate or not to subject two objects to head and modifiers, as a normal process, requires further investigation. However, the concept here is indicated as having a strong influence on creativity with respect to inventions.

In addition, the interaction of head and modifiers is more likely to produce inventions with a more complex form and a novel function when a living thing constitutes the modifier. This finding also manifests as a main effect of the modifier on the evaluation of creativity. This result supported second hypothesis. In short, relaxing the constraints attached to an object facilitates innovation with respect to complexity of form and novelty of function. Relaxing constraints would also favorably impact utility and creativity in inventions. 
However, the head of artificial object, in cases where the functional aspect is severely constrained, was highly evident when evaluated for utility and creativity. Negative correlations were found between utility and the function number of the head despite being insignificant, this finding may confirm the aforementioned implication. Utility, however, cannot be accounted for by the constraint when the low value of the correlation coefficient is considered. There is a possibility that the differences in the intrinsic property of the artificial object and living thing categories, and adjustments derived from combinations of functions (Wisniewski \& Gentner, 1991; Finke, 1995), relate closely to the head. Although further studies on the relevance of the head are warranted, it is evident that the emergence of creative and highly appreciated inventions can be facilitated by modifying the artificial object category to the living thing category as the head.

This evidence is consistent with the results of linguistic conceptual combination (Costello \& Kean, 2000). Artificial objects appropriate for the head which incline to the functional aspect in inventions. While living things suits modifier which affords conceptual fusion with the head to produce new forms and encourages novelties in inventions. We agree with Bock and Clifton (2000), who demonstrated that the special features of component elements on one side are mapped to those on the other side, with natural products manifesting more abundantly in this respect than artificial products. In conceptually combining two objects, it would be more effective to first establish the aspect of functional significance as the head before modifying the object with relaxed constraints. However, when an artificial object has been incorporated into a living thing, fusion of the artificial object with its potent constraints would proceed with the living thing, with its relaxed constraints, establishing the vague function, and lead to difficulty of emergence and then an unfavorable evaluation of an impractical conceptual combination.

Interestingly, interactions between head and modifiers, based on evaluation of utility and creativity evaluation, are involved in the combination of living thing + living thing constituents. Living thing + living thing combinations were rated with high utility, regardless of whether or not a living thing constituted the head. This finding suggests that, for hatching functionally creative inventions, it is critical to relax the modifier constraint. However, the yield is reduced by half with respect to creative inventions involving living thing + artificial object combinations. Our results indicate that relaxed rather than strict constraints would, on the whole, produce more creative inventions, although excessive relaxing of constraints directionality of thought (heads) may not lead to a positive result.

Furthermore, when focusing on constraints of knowledge representation, it is essential to subject a knowledge-derived conceptual structure for efficient information processing, though, constraint may become as strong as the elaboration of the conceptual structure. It has been emphasized that flexibility and dynamic extensibility are essential properties in creative thinking support (Kunifuji, 1993), and are significant as relaxing functions against constraints. As a strategically concrete approach to resolve the constraints of a knowledge representation or concepts, the original concept is grafted with another concept with fewer limitations so that discoveries, not conceived of in the pregrafted concept, may emerge in the newly structured concept. 


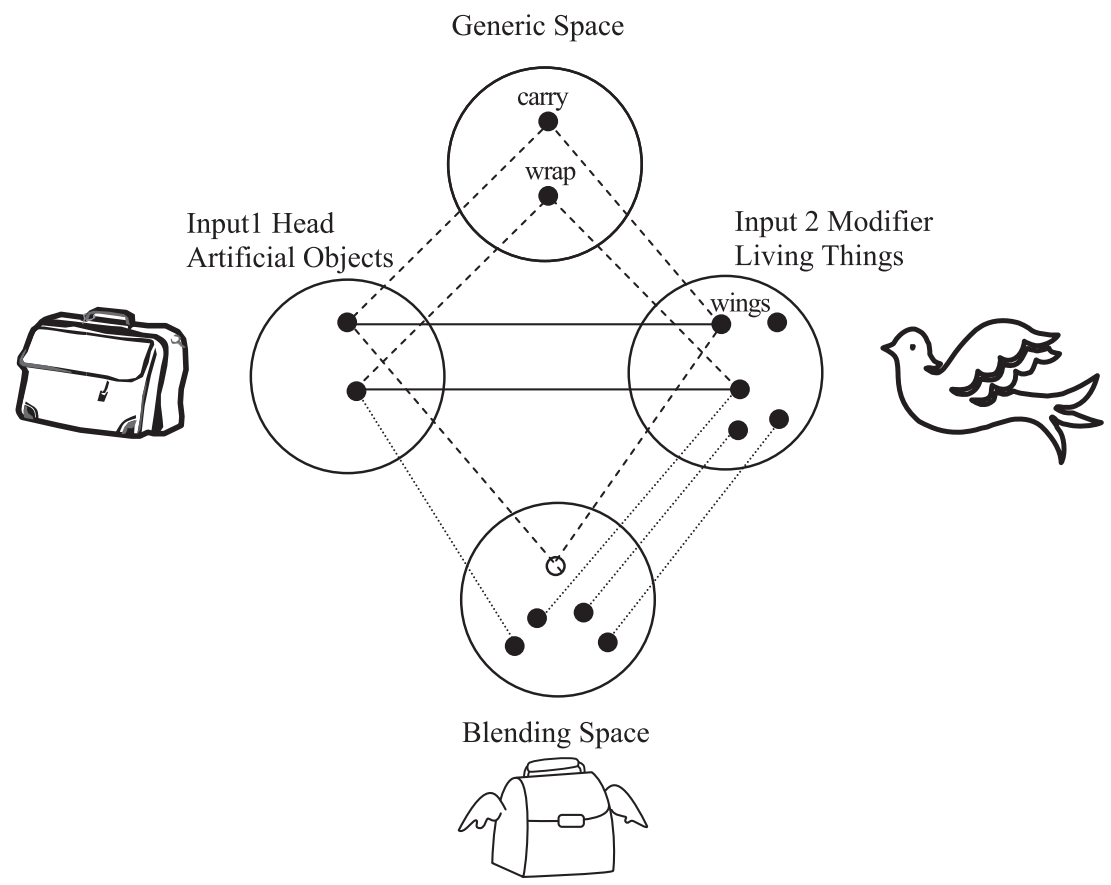

Fig. 5. The Conceptual Blending Theory

Fauconnier and Turner (2002) have proposed CB as a framework for explaining/ interpreting cognitive-linguistic phenomena such as analogy, metaphor, creativity or counterfactual reasoning. The Conceptual Blending Theory can provide a useful framework for understanding how constraints relate to create innovative combination. In $\mathrm{CB}$, elements from different mental spaces are aligned with one another as well as selectively projected to a blended space, yielding emergent meaning.

In this study, different mental spaces are suitable for head and modifier. The number of elements representing the degree of the constraints to let a function be prominent is different from artificial objects and living things. The result that the score of creativity was higher in LT + LT compared with $\mathrm{AO}+\mathrm{AO}$ indicated emergence was facilitated in cases where there are more elements than there are fewer elements. The creativity increases as a result that more elements are projected on blend space. However, the result that the score of creativity was higher in LT + AO compared with AO + LT indicated the combination of constrained head and relaxed modifier lead the innovative emergence. It was considered that constrained elements of which there was a prominent function projected in blend space and then provided a clear framework such as structure of language grammar. When thinking about the result of the utility, many loosely constrained modifiers may be united with various projected heads. After all, it seems that the degree of head constraint has acted as a convergent function when making a frame of the directionality of the invention and that the degree of modifier constraint has acted as a 
divergent function when an invention makes a newly revised frame.

Finally it was demonstrated that the result of the linguistic conceptual combination were applicable in the visualized conceptual combination. A way of thinking called head and modifier in the compound word could expand into visualized concept as a concrete object. In addition, this study was able to mention the morphological creativity by analyzing the created pictures. However, more study is needed in the future. Direct comparison between linguistic and visually conceptual combination is not accomplished because the conceptual combination condition of the word does not set it. Although it is necessary to examine this in future, there is a possibility that the model helps the scenes such as the realistic development of products considering aspect of visual design, if the model in which linguistic conceptual combination adds to morphological creativity would develop.

\section{REFERENCES}

Bock, J. S., \& Clifton, C. 2000. The role of salience in conceptual combination. Memory and Cognition, 28, 1378-1386.

Boden, M. A. 1992. The creative minds: Myths and mechanisms. New York: Basic Books.

Boden, M. A. 1995. Modeling creativity: reply to reviewers. Artificial Intelligence, 79, 161-182.

Costello, F. J., \& Keane, M.T. 1997. Polysemy in Conceptual Combination: Testing the Constraint Theory of Combination. In M. G. Shafto, P Langley (Eds.), Nineteenth annual conference of the cognitive science society (pp. 137-142). Hillsdale, NJ: Erlbaum.

Costello, F. J., \& Keane, M. T. 2000. Efficient creativity: Constraints-guided conceptual combination. Cognitive Science, 24, 299-349.

Finke, R. A. 1990. Creative imagery: Discoveries and inventions in visualization. Hillsdale, NJ: Lawrence Erlbaum Associates.

Finke, R. A. 1995. Creative insight and preinventive forms. In R. J. Stenberg \& J. E. Davidson (Eds.), The nature of insight (pp. 255-280). Cambridge, MA: MIT Press.

Finke, R. A., Ward, T. B., \& Smith, S. M. 1992. Creative cognition: Theory research, and applications. Cambridge, MA: MIT Press.

Fauconnier, G., \& Turner, M. 1998. Conceptual integration networks. Cognitive Science, Vol. 22, pp. 133187.

Fauconnier, G., \& Turner, M. 2002. The way we think: Conceptual blending and the mind's hidden complexities. Basic Books.

Gagné, C. L. 2000. Relation-based combinations versus property-based combination: A test of the CARIN theory and the dual-process theory of conceptual combination. Journal of Memory and Language, 42, 365-389.

Gagné, C. L., \& Shoben, E. J. 1997. Influence of thematic relations of the comprehension of modifier-noun combinations. Journal of Experimental Psychology-Learning Memory and Cognition, 23, 71-87.

Gelman, S. A. 1989. Children's use of categories to guide biological inferences. Human Development, 32 , 65-71.

Hauser, M. D. 1997. Artifactual kinds and functional design features: What a primate understands without language. Cognition, 64, 285-308.

Karmiloff-Smith, A. 1992. Beyond modularity: A developmental perspective on cognitive science. Cambridge, MA: MIT Press/Bradford Books.

Komazaki, H., Kusumi T., \& Shigemasu, K. 1998. Effects of abstract images on the conceptualization of an idea on inventions: changes in visualization from pre-invention form to an invention form. Cognitive Science, 5, 97-107 (in Japanese with English summary).

Kunifuji, S. 1993. The trend and relevant issues in research and development. Journal of Artificial 
intelligence, 8, 552-559 (in Japanese).

McRae, K., deSa, V. R., \& Seidenberg, M. S. 1997. On the nature and scope of featural representation of word meaning. Journal of Experimental Psychology: General, 126, 99-130.

Norman, D. A. 1991. Cognitive artifacts. In J.M. Carroll (Ed.), Designing interaction: Psychology at the human-computer interface (pp. 17-38). Cambridge: Cambridge University Press.

Norman, D. A. 1998. The invisible computer: Why good products can fail, the personal computer is so complex and information applicances are the solution. Cambridge, MA: The MIT Press.

Thagard, P., \& Verbeurgt, K. A. 1998. Coherence as constraint satisfaction. Cognitive Science, 22, 1-24

Wilkenfeld, M. J., \& Ward, T. B. 2001. Similarity and emergence in conceptual combination. Journal of Memory and Language, 45, 21-38.

Wisniewski, E. J. 1998. Property instantiation in conceptual combination. Memory \& Cognition, 26, 13301347.

Wisniewski, E. J., \& Gentner, D. 1991. On the combinatorial semantics of noun pairs: Minor and major disturbances to meaning. In G. B. Simpson (Eds.), Understanding word and sentence (pp. 241-284). Amsterdam: Elsevier.

Wisniewski, E. J., \& Love, B. C. 1998. Relations versus properties in conceptual combination. Journal of Memory and Language, 38, 177-202.

(Manuscript received August 22, 2007; Revision accepted January 9, 2009) 